\title{
Pemanfaatan Arang Aktif Sebagai Komponen Media Terhadap Pertumbuhan dan Produksi Tanaman Selada (Lactuca sativa L.)
}

\author{
Inka Dahlianah \\ e-mail: inkadahlianahrohim@gmail.com
Program Studi Biologi, Fakultas Matematika dan Ilmu Pengetahuan Alam Universitas PGRI Palembang

\begin{abstract}
This research have been carry out on january - March, 2016, at Sukarami field km 8 Palembang city, South Sumatra Province. The purpose of this research was to know influence of the addition of activated charcoal as soil enhancers of growth and yield of selada plant (Lactuca sativa L.). This research used randomized completely design with 1 factors. Each treatment was repeated 4 times. This treatment comparison of Soil : Activater Charcoal : Chicken Manure. This treatment are A0 : 6 soil : 0 Activated Charcoal : 1 Chicken Manure, A1 : 5 Soil : 1 Activated Charcoal : 1 Chicken Manure, A2 : 4 Soil : 2 Activated Charcoal : 1 Chicken Manure, A3 : 3 Soil : 3 Activated Charcoal : 1 Chicken Manure, A4 : 2 Soil : 2 Activated Charcoal : 1 Chicken Manure, A5 : 1 Soil : 5 Activated Charcoal : 1 Chicken Manure. The best result obtained at treatment of pameters high of plant is at treatment at A2 is $40,35 \mathrm{~cm}$, and wet weight of plant is $69,45 \mathrm{~g}$.
\end{abstract}

Keywords: activated charcoal, soil enhancer, chicken manure

\begin{abstract}
ABSTRAK
Penelitian ini untuk mengetahui manfaat arang aktif sebagai komponen media terhadap pertumbuhan dan produksi tanaman selada (Lactuca sativa L. ), telah dilakukan pada bulan Januari - Maret 2016 di kebun kelurahan Sukarami kecamatan Sukami kilometer 8 Palembang. Tujuan dari penelitian ini adalah untuk mengetahui pengaruh arang aktif sebagai pembenah tanah terhadap pertumbuhan dan produksi tanaman selada (Lactuca sativa L.). Metode penelitian menggunakan rancangan acak lengkap satu faktor dengan 6 perlakuan dan 4 ulangan. Perlakuan yang digunakan adalah perbandingan antara Tanah : Arang Aktif : Pupuk Kandang ayam. Perlakuan perbandingan yang digunakan adalah sebagai berikut: A0 : 6 tanah : 0 Arang Aktif : 1 Pupuk kandang ayam, A1 : 5 Tanah : 1 Arang Aktif : 1 Pupuk Kandang ayam, A2 : 4 tanah : 2 Arang Aktif : 1 Pupuk Kandang ayam, A3 : 3 Tanah : 3 Arang Aktif : 1 Pupuk Kandang ayam, A4 : 2 Tanah : 2 ArangAaktif : 1 Pupuk Kandang Ayam, A5 : 1 tanah : 5 Arang Aktif : 1 Pupuk Kandang ayam. Hasil penelitian menunjukkan bahwa hasil tertinggi pada parameter tinggi tanaman pada perlakuan A2 sebesar 40,35 cm, sedangkan berat basah tanaman pada perlakuan A2 sebesar 69,45 gram.
\end{abstract}

Kata Kunci: arang aktif, pembenah tanah, pupuk kandang 


\section{PENDAHULUAN}

Tanaman selada merupakan salah satu tanaman hortikultura. Hortikultura merupakan salah satu sub sektor penting dalam pembangunan pertanian. Secara garis besar, komoditas hortikultura terdiri dari kelompok tanaman sayuran (vegetables), buah (fruits), tanaman berkhasiat obat (medicinal plants), tanaman hias (ornamental plants) termasuk didalamnya tanaman air, lumut dan jamur yang dapat berfungsi sebagai sayuran, tanaman obat atau tanaman hias. Permintaan terhadap tanaman ini terus meningkat, seiring dengan meningkatnya jumlah penduduk dan konsumsi per kapita.

Salah satu kelompok sayuran lactuca sativa jenis selada adalah satusatunya jenis lactuca yang didomestikasi. Faktor-faktor yang berpengaruh terhadap kualitas selada yang dihasilkan diantaranya adalah kondisi tanah sebagai media, selada menghendaki tanah yang gembur, subur untuk hidupnya. Sistem pertanian konvensional atau pertanian yang seperti biasa dilakukan selama ini menggunakan pupuk anoraganik yang takarannya semakin tinggi dan berlebihan. Peningkatan takaran atau dosis yang diberikan menyebabkan terakumulasinya hara yang berasal dari pupuk anorganik di tanah maupun di perairan, tanah akan mengalami kejenuhan dan kerusakan, diantaranya struktur tanah menjadi keras,karena pupuk anorganik buatan pabrik diramu dengan kadar hara yang sangat tinggi sehingga berdampak negatif bagi lahan.

Menurut Dahlianah (2014), bahwa pemakaian pupuk anorganik yang relatif tinggi dan secara terus menerus serta pemakaian pestisida berbahan kimia dapat menimbulkan dampak negatif yang merugikan lahan, lahan pertanian mengalami degradasi atau kemunduran fungsi lahan akibat hilangnya bahan organik, dampak yang ditimbulkan dapat menurunkan produktivitas lahan pertanian, pestisida yang jatuh ke tanah menjadi permasalahan besar bagi lingkungan, karena dapat terbawa aliran air dan masuk ke sungai sehingga membahayakan biota air, hewan, dan manusia. Agar residu pestisida di dalam tanah tidak terbawa aliran air, residu tersebut perlu diikat atau diserap oleh bahan penyerap/pengikat. Salah satu bahan penyerap adalah arang aktif atau activated charcoal. Arang aktif diantaranya berasal dari bahan baku kayu, limbah pertanian seperti tongkol jagung, tempurung kelapa. Arang aktif mampu menyerap dan mengikat residu pestisida. Fungsi arang aktif selain berfungsi sebagai pembenah tanah sekaligus akan meningkatkan populasi mikroba pengurai yang ada didalam tanahi.

Pembenahan tanah perlu dilakukan, salah satunya dengan penambahan arang hayati atau arang aktif. Selama ini penggunaan arang dikenal hanya terbatas sebagai sumber energi (bahan bakar), baik itu arang batu bara maupun arang kayu, padahal arang dapat digunakan sebagai campuran pada pembuatan kompos agar kompos yang dihasilkan mempunyai kualitas yang lebih baik dan proses pengomposan menjadi lebih cepat. Selain itu arang dapat diaplikasikan pada tanah sebagai pembangun kesuburan tanah, terutama pada tanah yang miskin hara (Gusmailina, et al., 2000). Arang bermanfaat bagi perbaikan karakteristik dan kesuburan tanah (Gusmailina, 2010). Lebih lanjut hasil penelitian Siswandi, et al., (2015), pemberian arang sekam pada media memberikan pertumbuhan dan hasil selada yang terbaik.

Bertitik tolak dari permasalahn yang terdapat pada media tanah diatas, maka perlu di lakukan penelitian pemanfaatan arang aktif, berbahan baku kayu yang berasal dari pohon bakau sebagai komponen media, terhadap pertumbuhan dan produksi tanaman selada (Lactuca sativa L.). 


\section{BAHAN DAN METODE}

Penelitian ini telah dilakukan di kebun Kelurahan Sukarami Kecamatan Sukarami kilometer 8 Palembang. Pelaksanaan penelitian dimulai bulan Januari 2016 sampai dengan Maret 2016. Bahan penelitian adalah benih selada, pupuk kandang kotoran ayam, arang aktif, tanah.

Alat yang diperlukan adalah timbanganan, ember, cangkul, parang, sprayer, meteran, kantung plastik, tali rapia, wadah, spidol, karton, sendok semen, sarung tangan.

Penelitian ini menggunakan rancangan acak lengkap satu faktor dengan 6 perlakuan, dan 4 ulangan. Perlakuan yang digunakan adalah perbandingan antara Tanah : Arang Aktif : Pupuk Kandang. Perlakuan perbadingan yang digunakan adalah sebagai berikut:

A0 : 6 tanah : 0 Arang Aktif : 1 Pupuk kandang

A1 : 5 tanah : 1 Arang Aktif : 1 Pupuk Kandang

A2 : 4 tanah : 2 Arang Aktif : 1 Pupuk

Kandang

A3 : 3 tanah : 3 Arang Aktif : 1 Pupuk

Kandang

A4 : 2 tanah : 2 Arang aktif : 1 Pupuk Kandang

A5 : 1 tanah : 5 Arang Aktif : 1 Pupuk

Kandang

Bahan yang dipilih untuk pembuatan arang aktif yaitu kayu yang berasal dari pohon bakau, kayu tersebut dibersihkan, kemudian dibakar atau di aktivasi dengan suhu tinggi agar diperoleh arang aktif, selanjutnya arang ditumbuk, di ayak dengan diameter $0,25 \mathrm{~mm}$. Benih yang digunakan adalah benih yang memiliki viabel yang tinggi, Pembibitan di lakukan di wadah plastik, media pembibitan berupa tanah dan pasir, benih disebar, setelah bibit tanaman tersebut telah memiliki $3-5$ helai daun, dipindahkan ke polybag. Penanaman bibit selada dilakukan sore hari, setiap polybag ditanam lebih dari satu bibit tanaman selada.

Tanah yang diambil dari bekas lahan pertanian, dicampur dengan arang, dan pupuk kandang kotoran ayam sesuai dengan perlakuan aduk, untuk perlakuan kontrol tanpa penambahan arang aktif, setelah tercampur masukkan ke polybag, susun sesuai dengan denah rancangan yang digunakan yaitu rancangan acak lengkap. Pemeliharaan meliputi penjarangan dilakukan dengan meninggalkan 1 tanaman didalam polybag, penyiraman (tanah diusahakan senantiasa berada pada kondisi kapasitas lapang). Pengendalian hama dan penyakit dengan pestisida alami, sedangkan gulma dikendalikan dengan melakukan pe gulma secara mekanis dengan cara penyiangan. Panen dilakukan setelah tanaman selada berumur 35 hari setelah tanam. Setelah dipanen akar tanaman selada dioitong batas leher akar yang merupakan data berat basah tanaman selada.

Data kuantitatif diperoleh melalui pengukuran tinggi tanaman $(\mathrm{cm})$, jumlah helah daun (lembar), dan Berat basah (g) semua parameter diukur pada akhir penelitian.

Data yang diperoleh dari hasil penelitian diolah kemudian dianalisis dengan menggunakan analisis sidik ragam, untuk analisis keragaman dihitung dengan membandingkan $\mathrm{F}$ hitung dengan $\mathrm{F}$ tabel $5 \%$. Apabila nilai $\mathrm{F}$ hitung lebih besar dari pada nilai $\mathrm{F}$ tabel pada taraf nyata $\%$, perbedaan perlakuan dikatakan berbeda sangat nyata. Apabila nilai $F$ hitung lebih besar daripada $\mathrm{F}$ tabel pada taraf nyata 5\% tetapi lebih kecil daripda atau sama dengan nilai $\mathrm{F}$ tabel pada taraf nyata $1 \%$, perbedaan perlakuan dikatakan 
berbeda nyata. Apabila nilai F hitung lebih kecil dripada atau sama dengan nilai $\mathrm{F}$ tabel pada taraf nyata $5 \%$, perbedaan perlakuan dikatakn tidak berbeda nyata.

\section{HASIL DAN PEMBAHASAN}

Hasil analisis sidik ragam menunjukkan bahwa parameter tinggi tanaman dan berat basah berbeda sangat nyata dan jumlah helai daun tidak berbeda nyata. Jumlah helai daun yang tertinggi diperoleh pada perlakuan : 4 tanah : 2 Arang Aktif : 1 Pupuk Kandang(A2) yaitu sebesar 21,95 helai daun.

Tabel 2. Analisis sidikragam pemanfaatan arang aktif sebagai komponen media terhadap pertumbuhan dan produksi tanaman selada (Lactuca sativa L.) terhadap beberapa parameter pertumbuhan dan produks tanaman selada.sebagai berikut:

\begin{tabular}{|l|c|l|l|}
\hline \multirow{2}{*}{ Perlakuan } & \multicolumn{3}{|c|}{ Parameter } \\
\cline { 2 - 4 } & Tinggi tanaman & $\begin{array}{l}\text { Jumlah helai } \\
\text { daun }\end{array}$ & Berat basah \\
\hline $\begin{array}{l}\text { Pemanfaatan } \\
\text { arang aktif }\end{array}$ & $5,09^{* *}$ & $0,70^{\text {tn }}$ & $13,12^{* *}$ \\
\hline
\end{tabular}

Hasil analisis uji beda nyata terkecil $5 \%$ menunjukkan bahwa perlakuan pemanfaatan arang aktif berbeda tidak nyata, berbeda nyata dan sangat nyata antar perlakuan terhadap tinggi tanaman dan berat basah tanaman

Tabel 3. Pemanfaatan arang aktif sebagai komponen media terhadap tinggi tanaman selada (Lactuca sativa $\mathrm{L}),(\mathrm{cm})$.

\begin{tabular}{|l|l|}
\hline Perlakuan & Rerata (cm) \\
\hline A0 & $\mathbf{3 3 , 8 2}$ a \\
\hline A1 & 36,42 a \\
\hline A2 & 40,35 bc \\
\hline A3 & 39,47 b \\
\hline A4 & $37,65 \quad$ b \\
\hline BNT 5 \% :3,42 & \\
\hline
\end{tabular}

Keterangan: Angka yang diikuti huruf yang sama tidak berbeda nyata pada uji BNT $5 \%$.

Pada taraf uji $5 \%$ perlakuan A2 berbeda tidak nyata dengan perlakuan A3 dan A4 dan berbeda nyata dengan perlakuan lainnya, perlakuan A0 dan perlakuan A1, perlakuan a1 dan A2 tidak berbeda nyata dengan prlakuan A5. Angka tertinggi tinggi tanaman selada diperoleh 
pada perlakuan A2 yaitu sebesar 40, 35 $\mathrm{cm}$.

Berdasarkan tabel 3. perlakuan tertinggi diperoleh pada perlakuan A2 yaitu tinggi tanaman diperoleh sebesar $40,35 \mathrm{~cm}$, hal ini menunjukkan respon tanaman terhadap pemberian arang lebih baik dibandingkan dengan perlakuan lain, walaupun perlakuan A3 dan A4 menunjukkakan respon yang baik juga yitu 39,47 dan 37,65. Hal ini sesuai dengan pendapat Herman, dkk, (2011), bahwa pemberian arang dengan dosis $5 \%$ memberikan respon yang lebih baik terhadap laju pertumbuhan tinggi tanaman Michelia montana yaitu sebesar $4,85 \mathrm{~cm}$, dibanding dengan perlakuan dosis arang $15 \%$ dan $10 \%$, dan angka terrendah diperoleh pada perlakuan tanpa pemberian $0 \%$, yaitu sebesar $0,65 \mathrm{~mm}$. lebih lanjut menurut Gusmalina et al, 2000) penambahan arang aktif bahan baku dari bambu pada media tumbuh dapat meningkatkan pertumbuhan tinggi anakan Eucalyptus urophylla lebih baik dibandingkan dengan kontrol.

Tabel 4. Pemanfaatan arang aktif sebagai komponen media terhadap berat basah tanaman selada (Lactuca sativa L,) (gram).

\begin{tabular}{|l|l|}
\hline Perlakuan & Rerata (gram) \\
\hline A0 & 33,00 a \\
\hline A1 & 34,57 a \\
\hline A2 & $69,45 \quad$ c \\
\hline A3 & $67,50 \quad$ c \\
\hline A4 & $67,30 \quad$ bc \\
\hline A5 & $64,97 \quad$ b \\
\hline BNT 5 : 5,99 & \\
\hline
\end{tabular}

Keterangan: Angka yang diikuti huruf yang sama tidak berbeda nyata pada uji BNT $5 \%$.

Pada taraf $5 \%$ perlakuan A2 dan A3 berbeda tidak nyata dengan perlakuan $\mathrm{A} 4$, dan A4 tidak berbeda nyata dengan A5 dan berbeda nyata dengan perlakuan lainnya, serta perlakuan A2 dan A3 berbeda nyata dengan perlakuan A5 dan berbeda sangat nyata dengan perlakuan A0 dan A1. Angka tertinggi berat basah tanaman selada diperoleh pada perlakuan A2 yaitu sebesar 69,45 gram.

Berdasarkan tabel 4 perlakuan tertinggi diperoleh pada perlakuan A2 yaitu tinggi berat basah tanaman diperoleh sebesar 69,45 gram. Berdasarkan hasil penelitian Juliana, dkk, (2015), pemberian arang sekam dapat meningkatkan bobot 1000 bulir, dan bila ada kandungan logam berat $\mathrm{pb}$ maka arang sekam dapat menurunkan kadar logam pb dalam tanah. Fungsi lain arang aktif adalah dapat menurunkan logam berat berbahaya bagi tanaman. Selain itu arang aktif juga mengandung bahan organik yang cukup tinggi.

\section{KESIMPULAN}

Adapun kesimpulan dari hasil penelitin ini sebagai berikut bahwa hail tertinggi diperoleh pada parameter tinggi tanaman dan berat basah tanaman pada perlakuan A2 (4 tanah: 2 Arang Aktif: 1 Pupuk kandang. Parameter tinggi tanaman 
diperoleh sebesar 40,35 $\mathrm{cm}$, dan berat basah tertinggi sebesar 69, 45 gram.

\section{DAFTAR PUSTAKA}

Dahlianah, I., 2014. Pupuk Hijau Salah Satu Pupuk Organik Berbasis Ekologi Klorofil IX - 2: 54-56 Desember 2014. ISSN 2085 -9600

Gomez, K.A. and Arturo A.G. 1984. Statistical Procedurs for Agricultural Research. Publishing John Wiley and Sons, Inc.

Gusmailina,G.Pari,S.Komarayati,(2000) .The Utilization Technology on Charcoal as a Soil Conditioning (Project Report). Bogor:Forest Products Research Centre.

Gusmailina,G.Pari,S.Komarayati,S.Rost iwati,(2010) Alternatif Arang Aktif sebagai Soil conditioning pada Tanaman. Buletin Penelitian Hasil Hutan19(3).

Herman, H.,C.H. Siregar, 2011. Pengaruh Aplikasi Arang tergadap pertumbuhan awal Michelia Montana Blume dan perubahan sifat kesuburan tanah pada tipe tanah Latosol. Jurnal Penelitian Hutan dan Konservasi Alam. Vol 8 No. 1:6585, 2011.

Juliana, I.,Sarifuddin, Jamilah, 2015. Pemberian zeolite dan arang sekam pada lahan sawah tercemar limbah pabrik terhadap pb tanaman dan tanaman padi. Jurnal online. Agroekoteaknologi. Vol.3, No.2: 703-709. Maret 2015

Siswadi, Teguh Yuwono. 2013. Uji Hasil Tanaman Sawi pada Berbagai MediaTanamansecara Hidroponik. Jurnal Innofarm, Vol. II. No. 44-50 